\title{
Sleep disorders in adults and shift workers
}

\author{
Erişkinde ve vardiya usulü çalışanlarda uyku bozuklukları
}

\author{
Saylav Bora (iD, Agit Akgül(i), Güner Yurtsever (i) \\ Department of Emergency Medicine, İzmir Katip Çelebi University Atatürk Training and Research Hospital, İzmir, Turkey
}

\begin{abstract}
Sleep disorders, including insomnia and sleep-disordered breathing are common in elderly adults and prevent independent living by reducing daily functioning. Studies show that treatment of sleep disorders, may improve symptoms in elderly patients, even in scope of comorbid medical and mental health conditions. Research has been conducted on the effect of shift work on both physical and mental health. Shift workers have complaints of loss of appetite, constipation, dyspepsia, and abdominal pain and have high incidence of peptic ulcer. This review discusses similar sleep disorders in the elderly and shift workers.
\end{abstract}

Keywords: Mental health, shift workers, sleep disorder.

$\ddot{O Z Z}$

Insomnia ve uykusuda solunum bozukluğu dahil uyku bozuklukları yaşlı erişkinlerde sık görülür ve günlük işlevleri azaltarak bağımsız yaşamayı engeller. Araştırmalar, uyku bozukluklarının tedavisinin, yaşlı hastalarda eşlik eden tıbbi ve zihinsel sağlık koşulları bağlamında bile, semptomların iyileştirebileceğini göstermektedir. Vardiyalı çalışmanın gerek fiziki gerekse mental sağlık üzerine etkisini araştıran çalışmalar yapılmıştır. Vardiyalı çalışanlar iştah azalması, kabızlık, hazımsızlık ve karın ağrısından şikayetçidir ve peptik ülser insidansı yüksektir. Bu derlemede yaşıllar ve vardiya usulü çalışan kişilerin benzer uyku bozuklukları tartışıldı.

Anahtar sözcükler: Akıl sağlığı, vardiyalı çalışanlar, uyku bozuklukları.

Sleep varies with age and non-pathologic changes in sleep emerge with the normal aging process. Total sleep time (TST) is relatively shorter in the elderly compared to young adults; TST declines until about age 60 and stabilizes for the rest of life. This is due to a combination of physiologic changes in sleep, changes in sleeping habits, and increased rate of sleep disorders.

Elderly adults spend a lower percentage of sleep time in both slow waves (deep sleep) and REM sleep compared to young adults and have slightly increased time it takes in falling asleep. The number of wakes after falling asleep and total waking time also increases with age; however, elderly adults do not experience more difficulty compared to young adults in falling back asleep after stimulation. ${ }^{[1]}$ Additionally, elderly adults allocate more time to sleep throughout the day. Melatonin secretion and circadian rhythm amplitude decreases in older adults. ${ }^{[2]}$ After age 20, the Circadian rhythm gradually shifts (earlier shift), elderly adults begin to sleep earlier in the evenings and wake up earlier in the mornings. ${ }^{[3]}$ Although recent studies have shown that the rate of subjectively perceived sleep disorder actually declines in age groups, ${ }^{[4]}$ non-pathological changes in sleep may increase susceptibility to the development of sleep disorders such as insomnia. ${ }^{[5]}$ 


\section{SLEEP DISORDERS IN ELDERLY ADULTS}

Sleep disorders including insomnia and sleepdisordered breathing (SDB) are more common in elderly adults and prevent independent living by reducing daily functioning. Studies show treatment of sleep disorders, even within the context of comorbid medical and mental health conditions, may improve symptoms in elderly patients. Each of these common sleep disorders is discussed below.

\section{Sleep-disordered breathing)}

Sleep-disordered breathing occurs when the individual stops breathing repeatedly or there is a decrease in airflow during sleep. Apnea occurs when air flow completely stops for at least 10 seconds, and hypopnea when airflow decreases in a period of at least 10 seconds leading to decreased oxygen saturation. Obstructive sleep apnea (OSA) occurs when narrowing of the upper respiratory tract blocks breathing, and central sleep apnea (CSA) is the loss of respiratory effort. Sleep apnea is typically diagnosed when the average number of respiratory disorders or the apnea-hypopnea index (AHI) is 15 or more, or five or more, with associated symptoms such as excessive daytime sleepiness.

The American Academy of Sleep Medicine $(\mathrm{AASM})^{[6]}$ has presented guidelines for diagnosing OSA. Regardless of age, all patients suspected of OSA must undergo a comprehensive clinical evaluation that includes assessment of snoring, nocturnal choking or gasping, witnessed apneas, restlessness, and excessive daytime sleepiness. Respiratory, cardiovascular, and neurologic systems of patients should be physically examined and medical conditions associated with increased OSA risk such as obesity and hypertension should be identified. Patients with suspected sleep disorder should undergo polysomnography (PSG). If home sleep apnea test (HSAT) is not diagnostic for OSA, HSAT can be performed at home with PSG, in individuals with moderate to severe OSA. Use of HSAT equipment may be difficult for elderly adults and there is evidence that supports that technically insufficient HSAT may increase the need for laboratory PSG. ${ }^{[7]}$ When there are comorbid diseases such as some cardiorespiratory diseases and neuromuscular conditions that affect breathing in the elderly, PSG should be used instead of HSAT. ${ }^{[6]}$

Untreated sleep apnea is associated with a series of negative health outcomes such as increased mortality, hypertension, heart failure, cardiac arrythmia, cardiovascular events, cognitive disorders, insulin resistance, diabetes, and surgical complications. ${ }^{[8-13]}$ Correlation between sleep apnea and new onset epilepsy is especially strong in elderly adults. Patients with untreated sleep apnea have complaints of daytime sleepiness during situations that may affect their safety, such as driving. For most of the comorbid conditions listed above, treatment of sleep apnea decreases development of the condition, improves management, and reduces negative health outcomes of the comorbidity. ${ }^{[1]}$

In the general population, $9-38 \%$ of adults (6-19\% of adult women and $13-33 \%$ of adult men) have $\mathrm{AHI} \geq 5$ defined as OSA. ${ }^{[15]}$ When $\mathrm{AHI} \geq 15$ is used to define the disease, prevalence ranges from $6-17 \%{ }^{[15]}$ and this number increases to $36.5 \%$ in elderly adults. ${ }^{[16]}$ Sleep apnea is about 2-4 times more common in elderly adults compared to their middle ages ${ }^{[17]}$ and is estimated to be at least mild sleep-disordered breathing. Respiratory functions were impaired in $84 \%$ of males males with $\mathrm{AHI}>5$ and in $61 \%$ of women aged 60 and older. ${ }^{[18]}$ Sleep apnea rates are two times higher in elderly women than in elderly men. ${ }^{[18]}$

Continuous positive airway pressure (CPAP) or automatic positive airway pressure (APAP) is first-line treatment for OSA. Positive pressure works to keep the airway open. Trying out various positive airway pressure (PAP) masks that cover the patient's nose/mouth to find the most tolerable style, and educating the patient on both sleep apnea and PAP treatment may lead to improvement. Automatic positive airway pressure, which automatically sets the pressure according to apneas and hypopneas may be more comfortable than CPAP, which produces continuous pressure which may cause discomfort. Behavioral interventions include weight loss (if the patient is overweight), and decreasing alcohol intake, however, these have not been systematically researched in elderly patients. Opiod, sedative, or hypnotic drugs can be prescribed to elderly patients for pain, anxiety, or difficulty falling asleep, but should be used with caution as they may worsen SDB. 


\section{Insomnia}

According to the Diagnostic and Statistical Manual of Mental Disorders (DSM-5), insomnia is a significant disturbance or functional disorder defined as dissatisfaction with quantity or quality of sleep characterized by difficulty falling or staying asleep and waking early in the morning. For insomnia diagnosis, sleep disorder must occur at least three nights a week for at least three months. Insomnia prevalence is 5-8\% among elderly adults. ${ }^{[19]}$ Sleep complaints that are responsive to insomnia treatment range between $30-60 \% .^{[20]}$

Insomnia may atypically occur in elderly adults secondary to other medical and psychiatric disorders including chronic pain and neurologic disorders; however, insomnia mostly represents an independent unsolved clinical condition even when comorbidities are optimally managed.

Elderly adults usually increase their time laying down after retirement, which contributes to development and progression of insomnia when laying down time is longer than sleep time. Primary sleep disorders, drugs, and psychiatric disorders are generally associated with insomnia, and there is evidence that focusing on insomnia may improve the accompanying symptoms and conditions. Some elderly adults use alcohol instead of medication to fall asleep or cope with pain, which increases sleep disruptions and may increase insomnia.

In order to diagnose insomnia, a clinical interview must be held to determine factors affecting sleep history, and later medical evaluations may be necessary to assess factors that aggravate poor sleep. Although not recommended for insomnia, polysomnography can be used to rule out other sleep disorders. Elderly patients who present with cognitive disorders may provide unreliable history and interviewing the caretaker may provide additional helpful information. Patients may be also asked to keep a sleep diary for one week or more, including time spent in bed, total sleep time, number of times waking up, and duration. Other factors that may affect sleep including timing of taking drugs and substance abuse may also be recorded to provide the clinician with a comprehensive outlook. Actigraphy is a wristworn device used to estimate sleep activity may also grant additional data. It may be less helpful in insomnia diagnosis, since it cannot distinguish between laying down and falling asleep, but can show a better clinical picture of cognitively impaired and less active patients (instead of relying on a solely subjective sleep report). ${ }^{[19,20]}$

Insomnia treatment should address main conditions. Hypnotic agents in elderly patients are associated with increased adverse side effects, although they are typically reversed when the drug is discontinued, including numbness or fatigue, headache, and gastrointestinal discomfort, and hypnotics are associated with falling and vehicle accidents in the elderly. ${ }^{[21]}$ Effects of hypnotics on elderly adults, such as metabolic changes, increased risk of falling and confusion, and increased susceptibility of the central nervous system to depression, contributes to potential worsening of OSA and multiple drug use. Use of long-acting drugs should be avoided due to active metabolites and half-life longer than one day. Furthermore, because of risk of abuse, psychological dependency should also be considered. Some drugs such as benzodiazepines disrupt sleep structure and other drugs including many over-the-counter sleeping aids may also cause worrisome anticholinergic effects and cognitive impairments, especially in elderly patients. There is evidence that melatonin may reduce the time it takes to fall asleep and number of times waking up at night with very low side effects, particularly in elderly patients with low melatonin production, ${ }^{[2]}$ however there is not enough data to support its use in standard treatment of insomnia in the elderly.

First-line treatment of chronic insomnia is not pharmacologic. Cognitive Behavioral Therapy is an evidence-based treatment of insomnia in elderly adults. ${ }^{[20]}$ Cognitive Behavioral Therapy combines sleep restriction, stimulant control, sleep hygiene, and other behavioral and cognitive techniques. Sleep restriction reduces the amount of time the patient is in bed to improve sleep continuity, reduce sleep delay, and improve sleep hygiene. Improvement in sleep increases amount of time spent in bed.

Sleep compression is an alternative method that may be appropriate for adults who are more susceptible to the effects of daytime sleepiness, such as those at high risk of dozing off. Sleep compression lowers sleep time over a chronic 
period. Stimulus control is used to strengthen the relationship between bed and sleep and to weaken the relationship between sleep and maladaptive activities, including worry about sleep loss or rumination. Making and maintaining changes according to these recommendations may be difficult, therefore motivation techniques may helpful in increasing compliance. Other interventions include addressing false or invalid beliefs about sleep, and presenting strategies to reduce physiologic stimulus including muscle relaxation, guided images, and meditation. Cognitive behavioral therapy for insomnia (CBT-I) can be supported with a hypnotic drug.

Another important issue is the coexistence of OSA and insomnia in elderly patients. A recent study reported that $45 \%$ of elderly adults had moderate to severe OSA. ${ }^{[22]}$ More importantly, treatment of insomnia with CBT-I has similar effect in patients with and without mild-moderate OSA. ${ }^{[23]}$ Additionally, insomnia is a known risk factor of noncompliance to PAP treatment for OSA. ${ }^{[24]}$ In conclusion, elderly adults should be treated for both OSA and insomnia at the same time if possible.

\section{Circadian Rhythm Sleep-Wake Disorders (CRSWD)}

Circadian Rhythm Sleep-Wake Disorders occur when altered circadian rhythm or a mismatch between the person's circadian rhythm and the required sleep-wake program causes impaired sleep timing. Age-related neuronal loss of the suprachiasmatic nucleus, decreased melatonin production, and eye changes that decrease the ability of sunlight to reach ganglion cells in the retina responsible for maintaining circadian rhythm play a role in the desynchronization of circadian rhythms in elderly adults. Circadian rhythms are weaker and less sensitive to external stimuli and tend to change earlier with advancing age. Although these changes are normative, this pattern may have similar adverse health consequences to young individuals experiencing sleep programs that are misaligned with endogenous circadian rhythms. ${ }^{[25]}$ In some cases, misalignment may be significant enough to reach the threshold of a true sleep disorder. When misalignment causes hypersomnia or insomnia, and the person is significantly affected by sleep changes, diagnosis of CRSWD can be guaranteed regardless of how early the circadian rhythm is compared to typical pattern. ${ }^{[26]}$ For elderly patients with limited daytime undertakings, it may be easier to adjust their activity to accommodate changes in circadian timing. As a result, the effect of a less typical sleep schedule can be reduced in adults compared to young adults who actually have more occupational and other daytime demands. Evaluation of CRSWD should start by addressing other factors that may affect sleep-wake cycle or appear as CRSWD. These include depression, transient health changes, and sedative drugs. ${ }^{[27]}$

Advanced sleep-wake phase disorder (ASWPD) is the most common CRSWD in elderly adults and occurs when sleep onsets and waking times are earlier than desired and the patient cannot fix this "misalignment" on their own. Delayed sleep-wake phase disorder (DSWPD), which is more severe and more common in young adults, may also occur in the elderly. Delayed sleep-wake phase disorder occurs when the patient doesn't feel sleepy until late at night and have difficulty waking up at socially acceptable times in the morning. Like in ASWPD, the individual typically cannot synchronize their own sleep timing. In order to determine sleep-wake models, a sleep diary can be used for 1-2 weeks with actigraphy to support results.

The American Academy of Sleep Medicine (AASM) guidelines recommend evening light therapy for treatment of ASWPD. ${ }^{[28]}$ Evening bright light therapy through exposure to a bright box or outdoors can help delay sleepiness by shifting the sleep schedule to a later time. ${ }^{[27]}$ In order to measure responsiveness to treatment, keeping a sleep diary or actigraphy can be helpful in determining if the activity or rest period has shifted towards the desired direction. ${ }^{[26]}$ This guideline recommends morning light treatment for DSWPD patients. Cognitive and behavioral interventions may be helpful in improving sleep and increasing compliance to light therapy. Other treatments including melatonin administration, waking from sleep programming, and agents to promote sleeping and waking do not have enough evidence to be among recommended treatments for ASWPD. ${ }^{[28]}$

\section{Sleep disorders in emergency department personnel}

The most important complaint of shift workers is the disruption of sleep quality and sleep 
Table 1. Key points in successful night shifts

1. Undisturbed sleep in a dark and quiet room during the day

2. Avoiding daylight during the day

3. Avoiding noise with earplugs and sound-blocking devices

4. Freedom from activities and responsibilities during the day

5. Reminding family and friends not to disrupt sleep during the day

routine. ${ }^{[29]}$ Canessa et al. ${ }^{[10]}$ reported $62 \%$ of shift workers had complaints of sleep disorders while this rate was $20 \%$ in daytime shift workers. Night shift workers have relatively less productive sleep during the daytime compared to nighttime since their sleep is disrupted by noise, phone calls, and family. Daytime sleep is generally two hours shorter than nighttime sleep. Stage 2 and REM sleep durations are shorter. ${ }^{[29,30]}$

Studies have been conducted on both physical and mental health of shift workers. ${ }^{[31]}$ Shift workers have complaints of loss of appetite, constipation, dyspepsia, and abdominal pain and peptic ulcer incidence is high among these workers. This is because quality of nutrition consumed by night workers is lower, and they have higher consumption of caffeine, alcohol, and nicotine. ${ }^{[32]}$ In addition, associated accidents, errors, as well as divorce rates are higher compared to the general population. Night shift workers also have higher tendency to consume food with higher sodium and fat content. Risk of atherosclerotic diseases and heart attack and triglyceride levels were found higher in shift workers. Prevalence of depression and bipolar disorder was also found higher in shift workers. ${ }^{[32]}$

Some studies have linked infertility, premature labor, and low birth weight among childbirth risks in female shift workers. ${ }^{[33]}$ Bronchial secretions show increase at around 4-7 AM, indicating patients with asthma become ill more often during night shifts. Changes in sleep times in epileptic personnel also affects frequency of seizures. Similarly, personnel who experience migraine headaches have been reported to experience more episodes during shifts. Divorce, domestic violence, social isolation, and sexual dysfunction has also been found to be more common in shift workers. Female shift workers also develop more psychologic disorders and shift intolerance compared to males. ${ }^{[29]}$

Wakefulness is an important necessity for shift workers. Although it is recommended that an adult sleep nine hours for complete wakefulness under normal circumstances, shift workers are known to sleep less than workers with normal routine. ${ }^{[29]}$ In addition, a single night shift may not make much of a change in performance, but successive shift and poorly planned and improper sleep periods will result in an accumulation of fatigue and poor performance. ${ }^{[29]}$ The time of minimum wakefulness during a normal biological day is between 3-6 AM. Situations such as traffic accidents, workplace accidents, and improper treatment are common during these hours. The best example of this is the Chernobyl nuclear accident, which occurred around 4:00 AM. ${ }^{[4]}$ The main determinants of wakefulness throughout the day include the circadian phase, the night before sleep, the slow wave sleep during the night before sleep, and the regularity of sleep and work shifts. Performance also shows compatibility with body temperature. While better performance is shown when body temperature is high (middle

Table 2. Contraindications of the shift system

\begin{tabular}{ll}
\hline Partial contraindications & Absolute contraindications \\
\hline - Mild asthma & - Epilepsy requiring medical treatment \\
- History of sleep disorder & - Unstable angina with coronary disease \\
- Cardiac risk factors & - Astory of myocardial infarction \\
- History of depression & - Insulin-dependent diabetes \\
- History of seizures, no drug treatment & - Recurrent peptic ulcer \\
- Crequent indigestion & - Severe irritable bowel syndrome \\
- Familial instability & - Histonic depression of on long-term psychotropic use \\
- Loncreased family responsibilities &
\end{tabular}


of wakefulness period), performance is poor when body temperature is low in mornings and evenings. ${ }^{[7]}$ Memory best functions after a period of physiological rest and regeneration.

\section{Sleep related movement disorders}

Sleep related movement disorders inhibit sleep and are usually simple and stereotypical. Restless leg syndrome (RLS) or Willis-Ekbom Disease (WED) is the unbearable urge to move the legs accompanied by an "uncomfortable, burning, itching, or needles and pins" sensation that relaxes when moving the legs. While it typically occurs in the legs, it may also occur in the torso or upper limbs. It is worse during rest and increases in severity during evenings, which makes it difficult to fall and stay asleep, contributing to daytime sleepiness. Restless leg syndrome may be secondary to other idiopathic or medical conditions such as iron deficiency, peripheral neuropathy, and renal failure. About $10 \%$ of the general population report RLS symptoms and prevalence increases with age. RLS is more common in women than in men. ${ }^{[34]}$ Diagnosis is based on patient reports, although serum ferritin levels can be used to rule out akathisia, neuropathies, and other RLS-like syndromes to determine underlying or predisposing factors.

Following initial treatment, ${ }^{[35]}$ interventions should be towards underlying causes including discontinuation of drugs that worsen RLS such as SSRIs, TCA, lithium, and antipsychotics. Later when ferritin is $<50 \mathrm{mcg} / \mathrm{L}$, iron supplements can be taken with vitamin $\mathrm{C}$ to increase absorption. Treatment continues until ferritin is $>75 \mathrm{mcg} / \mathrm{L}$. If there is no response to iron replacement, RLS can be treated with dopaminergic agents such as pramipexole and ropinirole. These drugs should be used with caution as they may trigger sleep episodes and compulsive behaviors.

Second-line pharmacologic treatments for resistant cases include opioids and benzodiazepines that should be carefully used in elderly patients. High BMI, sedentary lifestyle, caffeine intake, and nicotine use is associated with RLS; moderate physical exercise and lowering caffeine and nicotine use is indicated. ${ }^{[34]}$

In most RLS patients, periodic leg movements of sleep (PLMS) is observed, which are repetitive cliché movements in the large toe, ankles, and sometimes knees and hips. The movements last a few seconds and generally occur 1-2 times a minute in the first period of night. Periodic leg movements of sleep increase with age. These movements cause significant sleep disorders. Periodic limb movement disorder (PLMD) is diagnosed with PSG and is characterized by 15 or more movements per hour of total sleep time combined with sleep or daytime fatigue. Although there is limited data supporting their productivity, patients may benefit from dopaminergic agents and the best approach is usually determining and treating associated sleep disorders including RSL and OSA. Periodic leg movements of sleep is frequent among people using antidepressants and drug evaluation may also be helpful.

\section{Parasomnias}

Parasomnias are a category of sleep disorders characterized by abnormal experiences during periods of transition between sleep and waking up. Individuals may experience abnormal movements, behaviors, emotions, perceptions, dreams, or physiologic stimuli. REM sleep behavior disorder (RBD) is the most common parasomnia in elderly adults and is characterized by strong motor behaviors while dreaming. RBD occurs when there is lack of normal muscle atonia during REM sleep, and may injure the patient or persons sleeping next to the patient. It is commonly associated with neurologic diseases such as Parkinson disease, multiple system atrophy, and Lewy body dementia. Idiopathic RBD may come before symptoms of neurodegenerative disease and requires neurologic monitoring. $\mathrm{RBD}$ is significantly more common in men compared to women and mean age of onset is 60.9 years. ${ }^{[36]}$ RBD diagnosis requires electroencephalography (EEG) and electromyography (EMG) to identify muscle atony in PSG. Comorbid deficiency, especially sleep disorder, initiates REM atonia and muscle atonia during REM sleep in an appropriate clinical setting.

Violent movements should be determined whether they are of OSA or RBD origin. RBD treatment is pharmacological and behavioral. Clonazepam is effective but may result in potentially negative outcomes in elderly patients. Although complex behaviors and mild-moderate leg movements continue, severe symptoms improve in the first week of treatment and there is 
no evidence of abuse or tolerance. ${ }^{[37]}$ Melatonin is more well tolerated among the elderly population and is an alternative therapy that is often used as the first-line agent in this group. ${ }^{[38]}$ Withdrawal from alcohol and barbiturates, caffeine use, and some drugs such as TCAs, MAO inhibitors, and SSRIs may induce or aggravate RBD. Interventions to strengthen circadian rhythm, changing drug regimens, and decreasing caffeine intake may improve RBD. Patient education and precautions are fundamental elements of RBD treatment and instructions include removing dangerous objects from the house, placing the mattress on the ground to prevent falling from the bed, and cushioning hard surfaces surrounding the bed.

\section{Dementia and long-term care}

Prevalence of dementia in adults aged 65 and older is estimated to range between $5-10 \%{ }^{[39]}$ and rates exponentially increase until at least age 90.[40] Changes in motor function, adverse effects of drugs, depression, autonomic disorders, pain, and other factors contribute to sleep disorders in dementia patients. While the definite cause is unknown, evidence points to treatment of sleep and circadian rhythm disorders relieving symptoms of some neurodegenerative diseases. ${ }^{[41]}$ Sleep disorders manifest in about $60 \%$ and insomnia in about $50 \%$ of dementia patients. Almost 90\% of patients diagnosed with Lewy body dementia (LBD) or Parkinson disease (PD) have sleep disorders, especially RBD and insomnia. ${ }^{[42,43]}$ Insomnia is the most common sleep disorder in vascular dementia; it is more common in patients with Alzheimer's disease with increased daytime sleeping. ${ }^{[4]}$ The most frequently observed pattern in all dementias is Irregular Sleep Wake Rhythm Disorder (ISWRD), in which circadian rhythm cannot be synchronized with sleep-wake cycle. Individuals may attain total sleep time but sleep occurs in fragmented night and day periods.

Drugs used in dementia may also affect sleep. For example, acetylcholinesterase inhibitors used to delay cognitive decline may increase wakes at night and nightmares, ${ }^{[43]}$ while drugs used in PD may affect REM sleep, causing daytime sleepiness, nighttime stimuli, hallucinations, and confusion. ${ }^{[45]}$ Antidepressants have been shown to increase or induce both idiopathic and secondary forms of RBD, while non-serotonergic bupropion is considered a first-line drug to treat depression in patients with RBD. ${ }^{[46]}$

Individuals with and without dementia face sleep-related difficulties in long-term care facilities. ${ }^{[34]}$ Noise and sharing rooms as well as variety of behavior of nighttime personnel are important environmental factors that may cause sleep disturbances. Individuals in nursing homes have less exposure to external light and have increased discomfort to light at night compared to individuals living in society. In addition, there is a direct correlation between sleep and activity level in individuals living in nursing homes, since those with sleep disorders have lower activity levels which is likely to further aggravate sleep disturbance. ${ }^{[47]}$ Because of environmental sleep disorders, those who live in long-term care facilities, especially those with Alzheimer's Disease, or those who are prone to sleep, such as those with low activity levels due to medical problems, can compensate for lost night's sleep by sleeping during the day. In contrast, falling asleep at night tends to be disrupted. Evaluation of sleep disorders in dementia patients is complicated due to memory deficiency and accompanying conditions. Other physical and mental health conditions and medications may contribute to sleep disorders, as is often the case with elderly adults. While depression decreases with age, ${ }^{[48]}$ $8-16 \%$ of the elderly have depression and most have symptoms of insomnia. ${ }^{[1]}$ Dementia is also associated with depression. ${ }^{[49]}$ Antidepressant treatment may be effective in treating insomnia, but side effects such as sedation and dizziness are especially worrisome in elderly patients with dementia. Limited cognitive level, characteristic of dementia, may affect accurate memory of relevant history and necessary sleep records for evaluation. Caregiver or others close to the patient may better comprehend the presence of sleep disturbance, although stereotypes that disturb sleep, normal for dementia, may prevent diagnosis. When an individual is accepted to have a sleep disorder, evaluating caregiver burden may be helpful in determining how to optimize caregiver support. Depending on the patient's presentation and circumstances, data from sleep logs can be improved with behavioral observations from caregivers or other people familiar with the patient's sleep routine. Actigraphy may also 
provide supportive information on the person's sleep/wake cycle. ${ }^{[50]}$

Considering the progressive nature of dementia, behavioral management of sleep disorders may be effective in early stages of the disease ${ }^{[43]}$ and may be improved with caregiver help; however, a few potential disadvantages of behavioral interventions should be initially considered. Elderly adults should be given a daily routine for bed and waking times, regardless of dementia. Stimulus control and sleep compression should be practiced. Naps can be planned but should be brief and consistent, and taken at the same time every day.

The AASM guidelines ${ }^{[28]}$ strongly opposes drug-induced sleep and states melatonin should be avoided. The guidelines also recommend light therapy for dementia patients who present with ISWRD.

Bright light therapy has been shown to increase productivity of sleep and increase TST. ${ }^{[4,51]}$ Placement of bright lights on walls or the ceiling may increase adherence and may be more tolerable than sitting in front of a conventional light box. Nursing home inhabitants have been shown to benefit from bright light exposure in mornings as "dawn to darkness" stimulation or bright light therapy that targets day long bright lights. ${ }^{[52]}$ While a study showed home-based bright light therapy did not improve sleep in dementia patients, sleep of caregivers improved. [51]

Obstructive sleep apnea is also common among elderly adults in long-term care facilities and treatment is recommended when it results in fragmented sleep or daytime sleepiness. ${ }^{[53]}$ Although positive airway pressure therapy has not been systematically researched in institutional environments, its benefits have been seen in patient groups with dementia, and reasonable PAP compliance has been achieved with caregiver

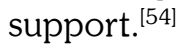

Factors associated with long-term care facilities may be disturbing for sleep, but these facilities are also typically well-equipped to implement sleepenhancing framework for dementia patients. Residents may be offered and encouraged exercise and social interaction and forming a routine can improve a range of sleep measures including regularly programmed meals and activities to reduce insomnia and regulate and shift the circadian rhythm. ${ }^{[52]}$ Intervention aimed at increased exposure to external sunlight, increase in physical activity, decrease in time spent in bed during the day, consistent bedtime routine, and reducing noise at night reduces number of wakes at night and increased active duration of rest/activity rhythm. ${ }^{[22]}$

In conclusion changes in sleep accepted as normal during the normal aging process include shorter sleep time at night, shorter slow-wave sleep and REM sleep, increased delay in falling asleep, and increased stimuli after start of sleep. Daytime sleepiness is also increased. Melatonin production is decreased, weakening the circadian rhythm. While these changes are not pathologic, sleep apnea, insomnia, circadian rhythm sleepwake disorders, and parasomnias are frequently observed in the elderly population. Many sleep disorders are associated with underlying conditions and drugs, and contributing factors must be medically evaluated and treated. Comprehensive sleep history is important in all sleep disorders evaluations. Sleep log supported by actigraphy or caregiver report provides valuables information in diagnosing insomnia and circadian rhythm disorders, while sleep apnea, PLMD, and RBD require sleep assessment complemented with EEG and EMG. Home sleep apnea testing may be used but PSG follow-up may be required, especially in this population which may face difficulty using HSAT.

Positive airway pressure treatment is recommended for sleep apnea accompanied by specific changes to the person's sleeping habits. Patients susceptible to negative outcomes due to other behavioral and cognitive techniques based on insomnia, daytime sleepiness, stimulus control, sleep hygiene, and presentation can be treated with sleep restriction or sleep compression. Studies on limited number of treatments of CRSWD in elderly adults showed positive results; however evening light therapy may contribute in delaying Circadian rhythms. Restless leg syndrome is pharmacologically treated and may improve with lifestyle changes. There is limited evidence supporting treatments of PLMD, however determining and treating underlying conditions and discontinuing certain drugs may improve symptoms. Behavioral interventions to 
increase safety accompanied by clonazepam or melatonin are first-line treatment approaches for restless leg and sleep disorder.

Although sleep disorders are more prevalent among elderly patients with dementia, they may be difficult to evaluate. Both dementia and living in a long-term care facility are associated with increased depression that affects sleep, and environmental factors related to long-term care facilities may also disrupt sleep. Interventions adapted to these difficulties, working with the patient's caregiver, installing a lighting system in the room, and even encouragement may increase participation in exercise and social activity offered by the facility.

\section{Declaration of conflicting interests}

The authors declared no conflicts of interest with respect to the authorship and/or publication of this article.

\section{Funding}

The authors received no financial support for the research and/or authorship of this article.

\section{REFERENCES}

1. Ohayon MM, Carskadon MA, Guilleminault C, Vitiello MV. Meta-analysis of quantitative sleep parameters from childhood to old age in healthy individuals: developing normative sleep values across the human lifespan. Sleep 2004;27:1255-73.

2. Pandi-Perumal SR, Zisapel N, Srinivasan V, Cardinali DP. Melatonin and sleep in aging population. Exp Gerontol 2005;40:911-25.

3. Roenneberg $\mathrm{T}$, Kuehnle $\mathrm{T}$, Juda M, Kantermann $\mathrm{T}$, Allebrandt K, Gordijn M, et al. Epidemiology of the human circadian clock. Sleep Med Rev 2007;11:429-38.

4. Grandner MA, Martin JL, Patel NP, Jackson NJ, Gehrman PR, Pien G, et al. Age and sleep disturbances among American men and women: data from the U.S. Behavioral Risk Factor Surveillance System. Sleep 2012;35:395-406.

5. McGrane IR, Loveland JG, de Leon J. Possible oxcarbazepine inductive effects on aripiprazole metabolism: A case report. J Pharm Pract 2018;31:361-3.

6. Kapur VK, Auckley DH, Chowdhuri S, Kuhlmann DC, Mehra R, Ramar K, et al. Clinical practice guideline for diagnostic testing for adult obstructive sleep apnea: An American academy of sleep medicine clinical practice guideline. J Clin Sleep Med 2017;13:479-504.

7. Zeidler MR, Santiago V, Dzierzewski JM, Mitchell MN, Santiago S, Martin JL. Predictors of obstructive sleep apnea on polysomnography after a technically inadequate or normal home sleep test. J Clin Sleep Med 2015;11:1313-8.

8. Aronsohn RS, Whitmore H, Van Cauter E, Tasali E.
Impact of untreated obstructive sleep apnea on glucose control in type 2 diabetes. Am J Respir Crit Care Med 2010;181:507-13.

9. Bradley TD, Floras JS. Obstructive sleep apnoea and its cardiovascular consequences. Lancet 2009;373:82-93.

10. Canessa N, Castronovo V, Cappa SF, Aloia MS, Marelli S, Falini A, et al. Obstructive sleep apnea: brain structural changes and neurocognitive function before and after treatment. Am J Respir Crit Care Med 2011;183:1419-26.

11. Kaw R, Michota F, Jaffer A, Ghamande S, Auckley $\mathrm{D}$, Golish J. Unrecognized sleep apnea in the surgical patient: implications for the perioperative setting. Chest 2006;129:198-205.

12. Kendzerska T, Mollayeva T, Gershon AS, Leung RS, Hawker G, Tomlinson G.Untreated obstructive sleep apnea and the risk for serious long-term adverse outcomes: a systematic review. Sleep Med Rev 2014;18:49-59.

13. Marin JM, Carrizo SJ, Vicente E, Agusti AG. Long-term cardiovascular outcomes in men with obstructive sleep apnoea-hypopnoea with or without treatment with continuous positive airway pressure: an observational study. Lancet 2005;365:1046-53.

14. Park JG, Ramar K, Olson EJ. Updates on definition, consequences, and management of obstructive sleep apnea. Mayo Clin Proc 2011;86:549-54.

15. Senaratna CV, Perret JL, Lodge CJ, Lowe AJ, Campbell BE, Matheson MC, et al. Prevalence of obstructive sleep apnea in the general population: A systematic review. Sleep Med Rev 2017;34:70-81.

16. Lee SD, Kang SH, Ju G, Han JW, Kim TH, Lee CS, et al. The prevalence of and risk factors for sleepdisordered breathing in an elderly Korean population. Respiration 2014;87:372-8.

17. Young T, Peppard PE, Gottlieb DJ. Epidemiology of obstructive sleep apnea: a population health perspective. Am J Respir Crit Care Med 2002;165:1217-39.

18. Heinzer R, Vat S, Marques-Vidal P, Marti-Soler H, Andries D, Tobback N, et al. Prevalence of sleepdisordered breathing in the general population: the HypnoLaus study. Lancet Respir Med 2015;3:310-8.

19. Gooneratne NS, Vitiello MV. Sleep in older adults: normative changes, sleep disorders, and treatment options. Clin Geriatr Med 2014;30:591-627.

20. McCurry SM, Logsdon RG, Teri L, Vitiello MV. Evidence-based psychological treatments for insomnia in older adults. Psychol Aging 2007;22:18-27.

21. Glass J, Lanctôt KL, Herrmann N, Sproule BA, Busto UE. Sedative hypnotics in older people with insomnia: meta-analysis of risks and benefits. BMJ 2005;331:1169.

22. Alessi C, Martin JL, Fiorentino L, Fung $\mathrm{CH}$, Dzierzewski JM, Rodriguez Tapia JC, et al. Cognitive Behavioral Therapy for Insomnia in Older Veterans Using Nonclinician Sleep Coaches: Randomized Controlled Trial. J Am Geriatr Soc 2016;64:1830-8.

23. Fung $\mathrm{CH}$, Martin JL, Josephson K, Fiorentino L, Dzierzewski JM, Jouldjian S, et al. Efficacy of Cognitive 
Behavioral Therapy for Insomnia in Older Adults With Occult Sleep-Disordered Breathing. Psychosom Med 2016;78:629-39.

24. Wickwire EM, Smith MT, Birnbaum S, Collop NA. Sleep maintenance insomnia complaints predict poor CPAP adherence: A clinical case series. Sleep Med 2010;11:772-6.

25. Marquié JC, Tucker P, Folkard S, Gentil C, Ansiau D. Chronic effects of shift work on cognition: findings from the VISAT longitudinal study. Occup Environ Med 2015;72:258-64.

26. Morgenthaler TI, Lee-Chiong T, Alessi C, Friedman L, Aurora RN, Boehlecke B, et al. Practice parameters for the clinical evaluation and treatment of circadian rhythm sleep disorders. An American Academy of Sleep Medicine report. Sleep 2007;30:1445-59.

27. Kim MJ, Lee JH, Duffy JF. Circadian rhythm sleep disorders. J Clin Outcomes Manag 2013;20:513-528.

28. Auger RR, Burgess HJ, Emens JS, Deriy LV, Thomas SM, Sharkey KM. Clinical Practice Guideline for the Treatment of Intrinsic Circadian Rhythm SleepWake Disorders: Advanced Sleep-Wake Phase Disorder (ASWPD), Delayed Sleep-Wake Phase Disorder (DSWPD), Non-24-Hour Sleep-Wake Rhythm Disorder (N24SWD), and Irregular Sleep-Wake Rhythm Disorder (ISWRD). An Update for 2015: An American Academy of Sleep Medicine Clinical Practice Guideline. J Clin Sleep Med 2015;11:1199-236.

29. Green-McKenzie J. Circadian rhythms and emergency medicine practice. http://www.emedicine.com/emerg/ topic835.html [Accessed: September, 2000]

30. Çevik AA. Acil servis ekibinin nitelikleri ve nöbet sistemi. III. Acil Tip Sempozyumu Özel Sayısı. Ulusal Travma Dergisi 2001;7:258-80.

31. Frese M, Okonek K. Reasons to leave shiftwork and psychological and psychosomatic complaints of former shiftworkers. J Appl Psychol 1984;69:509-14.

32. Spurgeon A, Harrington JM, Cooper CL. Health and safety problems associated with long working hours: a review of the current position. Occup Environ Med 1997;54:367-75.

33. Infante-Rivard C, David M, Gauthier R, Rivard GE. Pregnancy loss and work schedule during pregnancy. Epidemiology 1993;4:73-5.

34. Bloom J, Greenfield D, Cooke J. Adherence to continuous positiveairway pressure treatment in patients with Alzheimer's disease andobstructive sleep apnea. Am J Geriatr Psychiatry 2006;14:176-80.

35. Winkelman JW, Armstrong MJ, Allen RP, Chaudhuri KR, Ondo W, Trenkwalder C, et al. Practice guideline summary: Treatment of restless legs syndrome in adults: Report of the Guideline Development, Dissemination, and Implementation Subcommittee of the American Academy of Neurology. Neurology 2016;87:2585-93.

36. Rabadi MH, Mayanna SK, Vincent AS. Predictors of mortality in veterans with traumatic spinal cord injury. Spinal Cord 2013;51:784-8.

37. Gagnon JF, Postuma RB, Montplaisir J. Update on the pharmacology of REM sleep behavior disorder. Neurology 2006;67:742-7.

38. McGrane IR, Leung JG, St Louis EK, Boeve BF. Melatonin therapy for REM sleep behavior disorder: a critical review of evidence. Sleep Med 2015;16:19-26.

39. Hugo J, Ganguli M. Dementia and cognitive impairment: epidemiology, diagnosis, and treatment. Clin Geriatr Med 2014;30:421-42.

40. Jorm AF, Jolley D. The incidence of dementia: a metaanalysis. Neurology 1998;51:728-33.

41. Mattis J, Sehgal A. Circadian Rhythms, Sleep, and Disorders of Aging. Trends Endocrinol Metab 2016;27:192-203.

42. Guarnieri B, Adorni F, Musicco M, Appollonio I, Bonanni E, Caffarra P, et al. Prevalence of sleep disturbances in mild cognitive impairment and dementing disorders: a multicenter Italian clinical cross-sectional study on 431 patients. Dement Geriatr Cogn Disord 2012;33:50-8.

43. Dauvilliers Y. Insomnia in patients with neurodegenerative conditions. Sleep Med 2007;8:S27-34.

44. Zhou QP, Jung L, Richards KC. The management of sleep and circadian disturbance in patients with dementia. Curr Neurol Neurosci Rep 2012;12:193-204.

45. Adler $\mathrm{CH}$, Thorpy MJ. Sleep issues in Parkinson's disease. Neurology 2005;64(Suppl 3):S12-S20.

46. Trotti LM. REM sleep behaviour disorder in older individuals: epidemiology, pathophysiology and management. Drugs Aging 2010;27:457-70.

47. Garms-Homolovà V, Flick U, Röhnsch G. Sleep disorders and activities in long term care facilities--a vicious cycle? J Health Psychol 2010;15:744-54.

48. Fiske A, Wetherell JL, Gatz M. Depression in older adults. Annu Rev Clin Psychol 2009;5:363-89.

49. Newman SC. The prevalence of depression in Alzheimer's disease and vascular dementia in a population sample. J Affect Disord 1999;52:169-76.

50. Ancoli-Israel S, Martin JL, Blackwell T, Buenaver L, Liu L, Meltzer LJ, et al. The SBSM Guide to Actigraphy Monitoring: Clinical and Research Applications. Behav Sleep Med 2015;13(Suppl 1):S4-S38.

51. Sloane PD, Figueiro M, Garg S, Cohen LW, Reed D, Williams CS, et al. Effect of home-based light treatment on persons with dementia and their caregivers. Light Res Technol 2015;47:161-76.

52. Deschenes CL, McCurry SM. Current treatments for sleep disturbances in individuals with dementia. Curr Psychiatry Rep 2009;11:20-6.

53. Cooke JR, Ancoli-Israel S, Liu L, Loredo JS, Natarajan L, Palmer BS, et al. Continuous positive airway pressure deepens sleep in patients with Alzheimer's disease and obstructive sleep apnea. Sleep Med 2009;10:1101-6.

54. Ayalon L, Ancoli-Israel S, Stepnowsky C, Marler M, Palmer BW, Liu L, et al. Adherence to continuous positive airway pressure treatment in patients with Alzheimer's disease and obstructive sleep apnea. Am J Geriatr Psychiatry 2006;14:176-80. 